DOI: $10.4274 /$ jarem.galenos.2019.2444

J Acad Res Med 2020; 10(1): 103-5

\title{
A Case of Nodular Cystic Acne Treated with Systemic Dapsone
}

\author{
Munise Daye 이, Selami Aykut Temiz (1) \\ Necmettin Erbakan University Meram Faculty of Medicine, Department of Dematology, Konya, Turkey \\ Cite this article as: Daye M, Temiz SA. A Case of Nodular Cystic Acne Treated with Systemic Dapsone. JAREM 2020;10(1): 103-5
}

\begin{abstract}
Dapsone is an aniline derivative from synthetic sulfones. The mechanism of action of dapsone is obscure in inflammatory diseases; however, it is suggested to inhibit neutrophil chemotaxis and lysosomal enzymes. Acne vulgaris (AV) is a chronic inflammatory disorder of the pilo-sebaceous unit.

Herein we report a pediatric patient who was started systemic isotretionin due to severe nodular cystic AV but could not continue due to elevated liver enzymes and well response to systemic dapsone treatment. We consider that per-oral dapsone treatment may be a well-tolerated and effective treatment option in patients with moderate/severe, frequently recurring AV which is irresponsive to conventional therapies and may a good alternative to isotretionin particularly in pediatric cases.
\end{abstract}

Keywords: Dapsone, isotretinoin, nodulocytic acne

\section{INTRODUCTION}

Dapsone (4,4'-diamino diphenyl sulfone) is an aniline derivative from synthetic sulfones, which has both anti-bacterial and antiinflammatory effects. It was first used for the treatment of leprosy in 1940 and for the treatment of dermatitis herpetiformis and noninfectious inflammatory dermatoses thereafter (1).

Acne vulgaris (AV) is a chronic inflammatory disorder of the pilo-sebaceous unit, which is characterized by open and closed comedones, inflammatory papules, pustulae, nodules and cysts, which may lead to scar formation and altered pigmentation (2). Abnormal follicular keratinization, increased sebum production, Propionibacterium acnes colonization and inflammation are accused for the pathogenesis of AV (2).

Herein we report a pediatric patient who was started systemic isotretionin due to severe nodular cystic AV but could not continue due to elevated liver enzymes and well response to systemic dapsone treatment.

\section{CASE PRESENTATION}

A 14-year-old male patient was admitted to Dermatology Clinic due to widespread nodular cystic acne. Dermatologic examination revealed widespread nodular cystic acne lesions on the face, shoulders, and anterior side of the trunk (Figure 1). It was learned that he did not respond to systemic and local antibiotic therapies given due to nodular cystic AV.

He was planned to commence isotretionin $20 \mathrm{mg}$ daily and increase gradually; however, the dose was decreased to $10 \mathrm{mg}$ daily due to elevated liver enzymes at the first month of therapy. Isotretonin was discontinued at the control two weeks later due to the detection of aspartate aminotransferase $192 \mathrm{U} / \mathrm{L}$, alanine aminotransferase $406 \mathrm{U} / \mathrm{L}$ and gastro-enterology consultation was made. Viral panel results and auto-antibody test results (antinuclear antibodies, anti-mitochondrial antibodies, anti-smooth muscle antibodies) were negative. Elevated liver enzymes were suggested to be associated with isotretionin and turned to normal after the cessation of the drug.

ORCID IDs of the authors: M.D. 0000-0002-6614-1821; S.A.T. 0000-0003-4878-0045. 


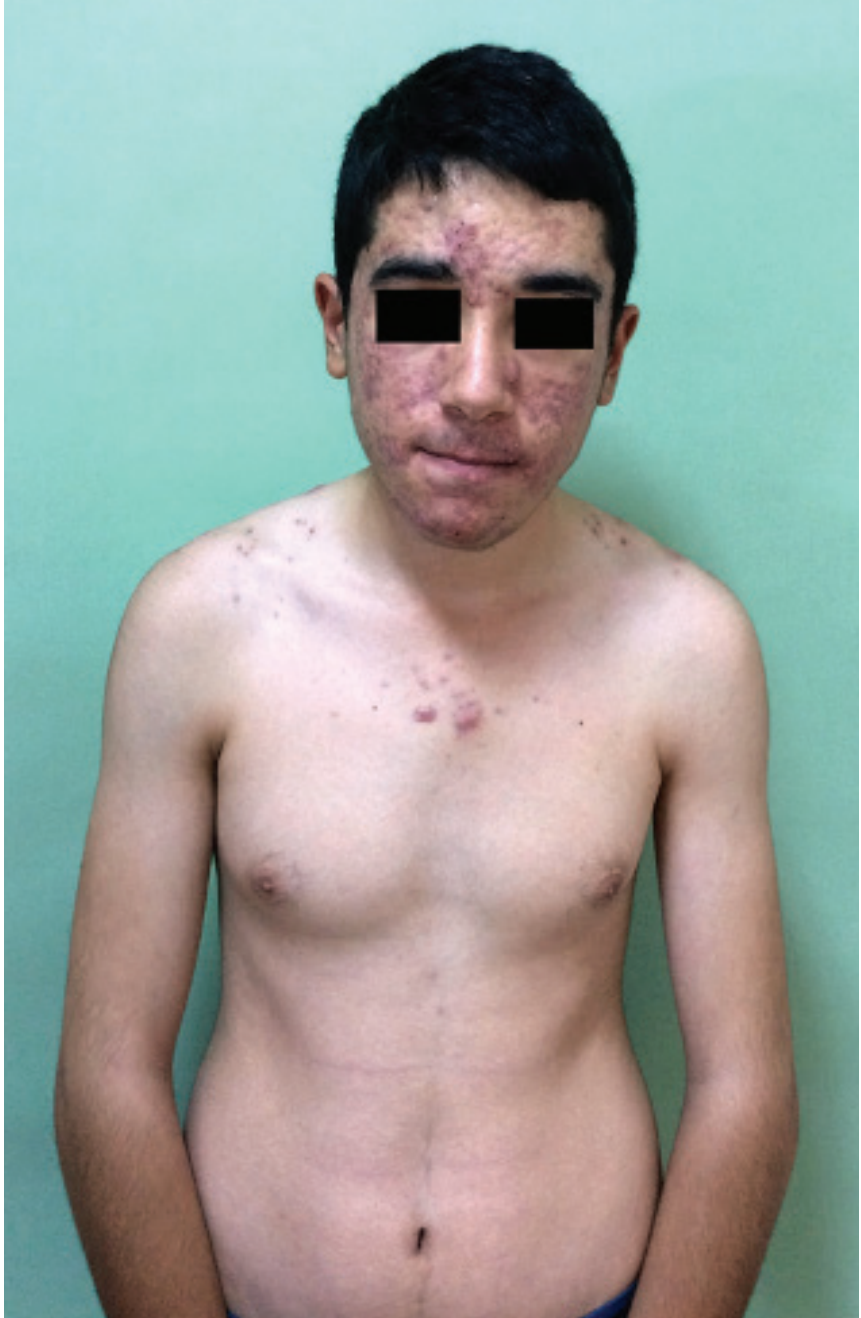

Figure 1. Widespread nodular cystic acne lesions on the face, shoulders, anterior side of the trunk

Dapsone treatment via per-oral route was planned as the patient could not tolerate isotretionin and was negatively affected from nodular cystic AV. Glucose-6-phosphate dehydrogenase enzyme level was normal. Lesions were detected to regress after using dapsone in the dose of $50 \mathrm{mg}$ daily so the dose was increased to $100 \mathrm{mg}$ daily. Lesions were dramatically regressed after using dapsone $100 \mathrm{mg}$ daily for 4 months and $50 \mathrm{mg}$ daily for 2 months. Whole blood count and routine biochemistry tests were found to be normal during the treatment. Active nodular cystic lesions dramatically regressed at the $6^{\text {th }}$ month of the treatment and atrophic scars developed (Figure 2). Informed consent was obtained from the patient and his mother for the publication of this case report and images.

\section{DISCUSSION}

AV is a chronic inflammatory disorder of the pilo-sebaceous unit which affects approximately $80 \%$ of adolescents and young adults (3). While topical treatment is sufficient in mild forms of $\mathrm{AV}$, systemic treatment is required in moderate and severe forms. Isotretionin used via per-oral route is the most effective therapeutic

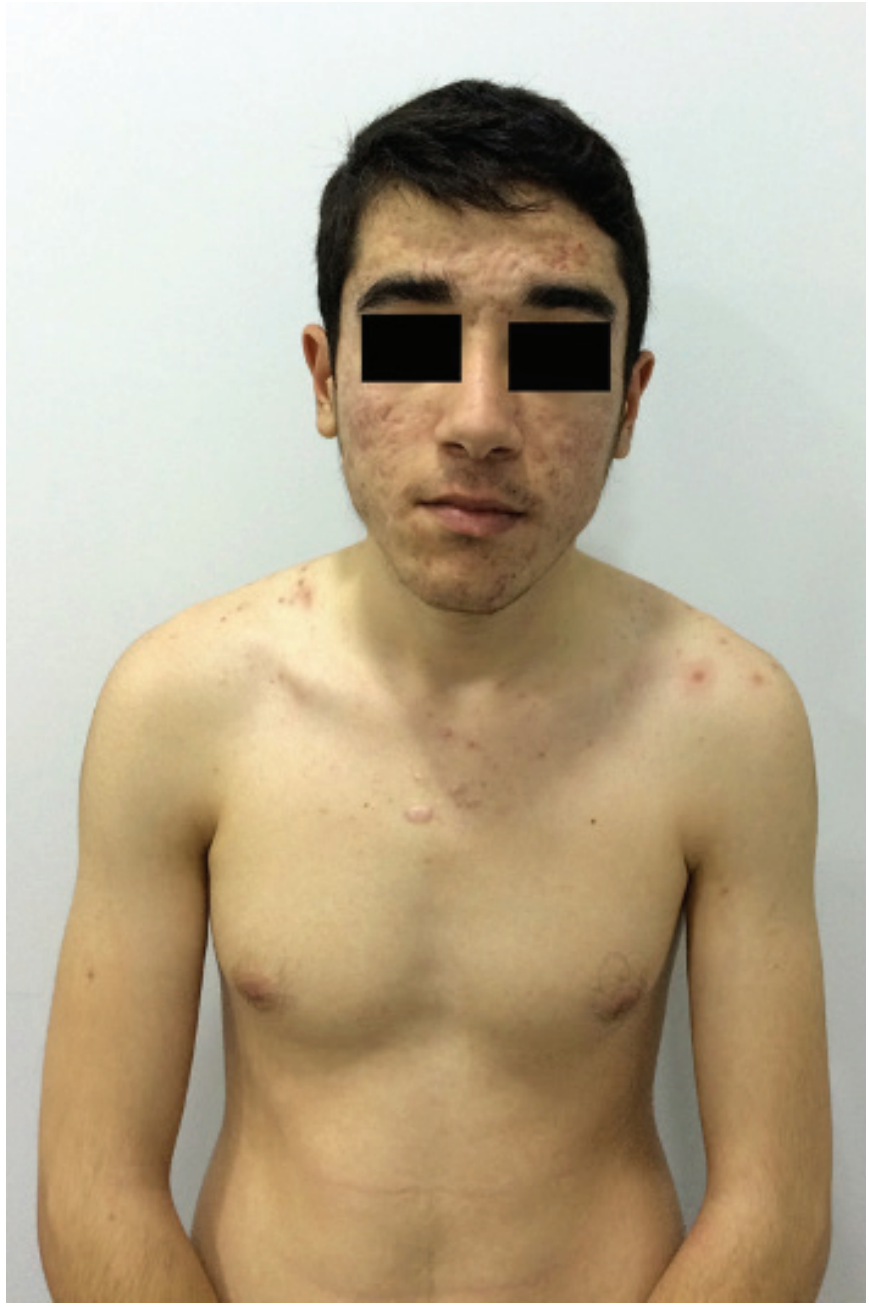

Figure 2. Active nodular cystic lesions dramatically regressed at the $6^{\text {th }}$ month of treatment and atrophic scars developed

agent used for the treatment of moderate/severe acne for longer than 30 years and it influences all factors in the pathogenesis of acne and provides long term remission (4). Isotretionin used via per-oral route which has tolerable muco-cutaneous and systemic side effects keeps its place in the treatment of acne due to its effectiveness and safety (5).

No consensus is available about an effective treatment option when isotretionin cannot be used due to toxicity. In literature, Didona et al. (6) have reported the use of dapsone in a 14-yearold patient whose acne progressed under isotreatinine treatment, and Wakabayashi et al. (7) reported a dramatic response with dapsone treatment in 5 Japanese patients. We planned to use dapsone in our patient who could not use systemic isotretionine due to elevated liver enzymes.

The mechanism of action of dapsone is obscure in inflammatory diseases; however, it is suggested to inhibit neutrophil chemotaxis and lysosomal enzymes (8). Dapsone is among the treatment options in diseases like bullous pemphigoid, eosinophilic folliculitis, Sweet syndrome, erythema elevatum diutinum, leukocytoclastic vasculitis, pyoderma gangrenosum, bullous form 
Peer-review: Internally peer-reviewed.

Author Contributions: Surgical and Medical Practices - M.D., S.A.T.; Concept - M.D., S.A.T.; Design - M.D., S.A.T.; Data Collection and/or Processing - M.D., S.A.T.; Analysis and/or Interpretation - M.D., S.A.T.; Literature Search - M.D., S.A.T.; Writing Manuscript - M.D., S.A.T.

Conflict of Interest: The authors have no conflict of interest to declare.

Financial Disclosure: The authors declared that this study has received no financial support.

\section{REFERENCES}

1. Ashurst JV, Wasson MN, Hauger W, Fritz WT. Pathophysiologic mechanisms, diagnosis, and management of dapsone-induced methemoglobinemia. J Am Osteopath Assoc 2010; 110: 16-20.

2. Kraft J, Freiman A. Management of acne. CMAJ 2011; 183: 430-5.

3. Leyden JJ. New understandings of the pathogenesis of acne. J Am Acad Dermatol 1995; 32: 15-25.

4. Brelsford M, Beute TC: Preventing and managing the side effects of isotretinoin. Semin Cutan Med Surg 2008; 27: 197-206.

5. Karadağ AS, Çalka Ö, Akdeniz N. Evaluation of side effects of isotretinoin in 150 patients with acne vulgaris. Turkderm 2011; 45: 37-42.

We consider that per-oral dapsone treatment may be a welltolerated and effective treatment option in patients with moderate/severe, frequently recurring $\mathrm{AV}$ which is irresponsive to conventional therapies and dapson can be used for $\mathrm{AV}$ in patients who improve severe side effects.

We believe that further prospective clinical studies that will be conducted with more patients and will investigate the effectiveness of dapsone in $\mathrm{AV}$ are required.

Informed Consent: Informed consent was obtained from the patient and his mother for the publication of this case report and images.
6. Didona D, Paolino G, Donati P, Muscardin LM. Resolution of nodulocystic acne with oral dapsone. Dermatol Ther 2017; 30.

7. Wakabayashi M, Fujii N, Fujimoto N, Tanaka T. Usefulness of dapsone for the treatment of Asian severe acne. J Dermatol 2013; 40: 502-4.

8. Braun DE, Krüger $H$, Kahlenberg V, Griesser UJ. Molecular Level Understanding of the Reversible Phase Transformation between Forms III and II of Dapsone. Cryst Growth Des 2017; 17: 5054-60.

9. Taylor SC, Cook-Bolden FE, McMichael A, Downie JB, Rodriguez DA, Alexis AF, et al. Efficacy, Safety, and Tolerability of topical dapsone gel, $7.5 \%$ for treatment of acne vulgaris by Fitzpatrick Skin Phototype. J Drugs Dermatol 2018; 17, 160-7.

10. Tan BB, Lear JT, Smith AG. Acne fulminans and erythema nodosum during isotretinoin therapy responding to dapsone. Clin Exp Dermatol 1997; 22, 26-7. 